\title{
Therapeutic Effectiveness of Cefoperazone for Community- Acquired Pneumonia and Associated Factors in a Tertiary Care Hospital, Vietnam
}

\author{
Cua Ngoc Le $e^{1,{ }^{*}}$, Duong Trung Nguyen ${ }^{2}$, Supreecha Kaewsawat ${ }^{1}$, Charuai Suwangbamrung ${ }^{1}$ and \\ Patthanasak Khammaneechan ${ }^{1}$ \\ ${ }^{1}$ Excellent Center for Dengue and Community Public Health, School of Public Health, Walailak University, Thailand \\ ${ }^{2}$ Graduate Master Program in Pharmacology and Clinical Pharmacy, Faculty of Pharmacy, HCM University of \\ Medicine and Pharmacy, Vietnam
}

\section{Article Info:}

Keywords:

Cefoperazone monotherapy

CURB-65 scores

antibiotic sensitivity testing

community-acquired pneumonia.

\section{Timeline:}

Received: February 13, 2021

Accepted: April 11, 2021

Published: June 02, 2021

Citation: Le CN, Nguyen DT, Kaewsawat

$\mathrm{S}$, Suwangbamrung $\mathrm{C}$,

Khammaneechan P. Therapeutic

effectiveness of cefoperazone for community-acquired pneumonia and associated factors in a tertiary care hospital, Vietnam. J Pharm Nutr Sci 2021; 11(1): 20-27.

\begin{abstract}
:
Purpose: This study aimed to (i) identify the pathogenic bacterial profile and Cefoperazone (CPZ) sensitivity; (ii) assess the therapeutic effectiveness of CPZ and (iii) determine factors associating with the treatment success.

Patients and methods: The retrospective study was conducted in Kien Giang hospital, Vietnam. Sample size was 210 medical records of community-acquired pneumonia (CAP) patients admitted to the hospital from January to December 2018. The Chi square and Fisher's exact test were used to determine factors associating with the treatment success such as age, gender, comorbidities, levels of CAP severity respiratory rate, $\mathrm{PaO} 2$, and laboratory findings of blood tests. Statistical significance was at level $\alpha=0.05$

Results: The main pathogenic bacteria were Klebsiella pneumoniae $(29.1 \%)$, Streptococcus pneumoniae (26.7\%) and Pseudomonas aeruginosa (14\%), and were highly susceptible to CPZ. Mean duration of obtaining clinical stability was 3.01 days. The obtainment of clinical stability through CPZ monotherapy on the third, fifth and seventh day of treatment process accounted for $78.9 \%, 87.6 \%$ and $100 \%$ of total cases, respectively. CPZ achieved a highly successful rate in the monotherapy $(79.07 \%)$ if the treatment was guided by antibiotic sensitivity testing results. The association between the treatment success and factors such as age, respiratory rate, and severity category of CAP were statistically significant $(p<0.05)$.

Conclusion: Minimizing CPZ resistance, and CPZ overuse during CAP therapy is necessary. The factors associating with the success of therapy are useful in predicting the prognosis of CAP patients, planning the sequential therapy, and determining hospital discharge.
\end{abstract}

DOI: https://doi.org/10.29169/1927-5951.2021.11.03

\footnotetext{
*Corresponding Author

E-mail: cua.le@wu.ac.th

Tel: +66931930737
}

(c) 2021 Le et al.; Licensee SET Publisher.

This is an open access article licensed under the terms of the Creative Commons Attribution Non-Commercial License (http://creativecommons.org/licenses/by-nc/3.0/) which permits unrestricted, non-commercial use, distribution and reproduction in any medium, provided the work is properly cited. 


\section{INTRODUCTION}

Community-acquired pneumonia (CAP) is a common infectious disease and also one of the leading causes of death among the elderly with comorbid diseases [1]. In the United States, more than 5 million CAP cases occur annually, and the cost of treatment for CAP is estimated at greater than $\$ 12$ billion annually [2]. One of the reasons for the increased cost of CAP treatment is the ineffective choice of antibiotic therapy, resulting from empirical therapy without detecting pathogens and determining the antibiotic susceptibility of bacteria [3]. Common CAP causative bacteria involve Grampositive cocci and Gram-negative bacteria such as Streptococcus pneumoniae, Klebsiella pneumoniae, Escherichia coli, Staphylococcus aureus, and Pseudomonas aeruginosa [4,5]. For treating CAP in Vietnam, public hospitals have been using antibiotics in the third generation Cephalosporin groups such as Ceftazidime and Ceftriaxone. Furthermore, Cefoperazone (CPZ) is also recommended in the treatment of CAP because this third-generation Cephalosporin antibiotic has a broad spectrum of activity against both Gram-positive and Gram-negative bacteria[6,7]. In Taiwan, Jien WL et al. have assessed the clinical effect of the combination drug therapy of CPZ-Sulbactam to be active against commonly encountered multidrug-resistant pathogens for hospitalacquired pneumonia (HAP) and healthcare-associated pneumonia [6-8]. However, CPZ monotherapy recently has been used to treat HAP and CAP in Vietnam, but the therapeutic effect of CPZ monotherapy has not been published [9]. In 2018, nearly 1,000 patients diagnosed with CAP were hospitalized and treated with CPZ monotherapy in Kien Giang tertiary care hospital. A comprehensive analysis of available data is necessary and useful to explore the features of pathogens and evaluate the effectiveness of CPZ monotherapy. Therefore, this retrospective study aimed to (i) identify bacterial pathogens and their antibiotic susceptibility to $C P Z$, (ii) assess the therapeutic effectiveness of CPZ monotherapy, and (iii) determine factors related to the treatment success among hospitalized CAP patients at the Department of General Internal Medicine in Kien Giang tertiary care hospital, Vietnam

\section{MATERIAL AND METHODS}

A retrospective study was used to analyze medical records of patients diagnosed with CAP who were admitted to the Department of General Internal Medicine of Kien Giang Tertiary Hospital from January
2018 to December 2018. The total population sampling was applied.

Inclusion criteria: patient's medical records having ICD10 diagnosis codes (International Classification of Diseases, Tenth Revision) from J12 to J18 (Diagnosis of (CAP) and treatment with CPZ from hospital admission to discharge or death or referral. Age $\geq 18$ years olds due to hospital admission only for adults.

\section{Exclusion Criteria}

- Coexistence with the following diseases or condition could cause biased outcome evaluations such as

- Acquired pulmonary tuberculosis, pulmonary cancer, pulmonary infarction, and HIV infection.

- Undergoing chemotherapy.

- Pneumonia was diagnosed 48 hours after admission: hospital-acquired pneumonia or healthcare-acquired pneumonia.

- Loss of treatment follow-up information from admission to discharge: referrals from other departments or from other hospitals, and discharge without hospital permission

After the screening process, there were 210 medical records to satisfy the criteria. Access to data of medical records was allowed by the board of directors of Kien Giang Tertiary Hospital. The research tool for data collection was approved by the Research Ethics Council of the HCM City University of Medicine and Pharmacy (Number: 017 - 173 / DD-YD issued on December 22, 2017).

\section{Evaluation of the Effectiveness of CPZ Monotherapy}

The initial CPZ therapy depended on the result of CPZ susceptibility of causative bacteria [9].The effectiveness of $\mathrm{CPZ}$ was evaluated based on the therapeutic response on the 5 th day of the treatment process as follows[10,11].

\section{Body temperature $\leq 37.8^{\circ} \mathrm{C}$ during 48 hours}

Only one sign showing clinical instability such as systolic blood pressure $\leq 90 \mathrm{~mm} \mathrm{Hg}$, respiratory rate $>24$ breaths $/ \mathrm{min}$, heart rate $>100$ beats/min, oxygen saturation pressure $\left(\mathrm{SpO}_{2}\right)<$ $90 \%$, or arterial oxygen partial pressure $\left(\mathrm{PaO}_{2}\right)<$ $60 \mathrm{~mm} \mathrm{Hg}$. 
Table 1: Elements of CURB-65 Score and Risk Stratification for Pneumonia

\begin{tabular}{|c|c|c|}
\hline CURB-65 & Clinical feature & Point \\
\hline \hline$(\mathrm{C})$ & Confusion & 1 \\
\hline$(\mathrm{U})$ & $\begin{array}{c}\text { BUN }>7 \mathrm{mmol} / \mathrm{L} \\
\text { or } 20 \mathrm{mg} / \mathrm{dL}\end{array}$ \\
\hline (R) & $\begin{array}{c}\text { Respiratory rate } \\
\geq 30 \text { breaths/min }\end{array}$ & 1 \\
\hline$(\mathrm{B})$ & Systolic BP< $90 \mathrm{mmHg}$ \\
Diastolic BP $\leq 60 \mathrm{mmHg}$ & 1 \\
\hline$(65)$ & Age $\geq 65$ & Management \\
\hline Total CURB-65 score & Risk group & Low risk, home treatment \\
\hline $0-1$ & 1 & Moderate risk, hospital admission \\
\hline 2 & 2 & High risk, manage in hospital as severe pneumonia \\
\hline $3-5$ & 3 & \\
\hline
\end{tabular}

Note: BUN (Blood Urea Nitrogen); BP (Blood Pressure).

The result of treatment that satisfies these criteria can conclude success or achieve therapeutic effectiveness.

\section{Factors Associated with the Therapeutic Effectiveness of CPZ}

According to Table 1, CAP severity was determined by the British Thoracic Society's CURB-65 score, which consists of 5 risk factors: new onset of confusion, blood urea nitrogen (BUN) $>7 \mathrm{mmol} / \mathrm{L}$ or $20 \mathrm{mg} / \mathrm{dL}$, respiratory rate $\geq 30$ breaths $/ \mathrm{min}$, systolic blood pressure $<90 \mathrm{mmHg}$ or diastolic $\leq 60 \mathrm{mmHg}$, and age $\geq 65$ years. Each risk factor scores one point, and the CURB-65 scores range from 0 to 5 . The interpretation of CURB-65 scores is as follows: (i) 0-1 point: probably suitable for home treatment or outpatient care; low risk of death; (ii) 2 points: consider hospital supervised treatment or hospital admission; moderate risk of death. (iii) $\geq 3$ points: manage in hospital as severe pneumonia; high risk of death; Intensive Care Unit (ICU) admission with a score from 4 to 5 [1,12]. Factors related to the therapeutic effectiveness of $C P Z$ include the severity category of CAP based on CURB-65, comorbid chronic diseases, respiratory rate, $\mathrm{PaO} 2$, and laboratory findings of blood tests such as BUN, Creatinine, Albumin, and $\mathrm{C}$ - reactive protein (CRP).

\section{Data Analysis}

Data analysis was done with IBM SPSS statistical software 20. Results of descriptive statistics were frequencies and percentages to give the proportions of pathogens, CPZ susceptibility to pathogens, and therapeutic effectiveness. A Chi-square test was used to determine factors related to therapeutic effectiveness. The odds ratio (OR) and corresponding 95\% confidence interval $(\mathrm{Cl})$ for each variable were calculated. A P-value less than 0.05 was considered statistically significant.

\section{RESULTS}

\section{Patient's Characteristics}

The study involved 210 inpatients' medical records that were diagnosed with CAP. Among them, 153 cases $(72.9 \%)$ were $\geq 65$ years old; 91 (43.3\%) were men, and $119(56.7 \%)$ were women. The mean age of the cases was $70.6 \pm 15.1$ years.

\section{Bacterial Pathogens and Sensitivity to CPZ}

The analysis of medical records revealed that $142 / 210$ cases $(67.6 \%)$ had the bacterial sputum culture for the identification of bacterial pathogens, and 86 cultured samples were positive. The result of antimicrobial susceptibilities of CPZ is shown in Table 2 . The rates of CAP cases caused by Klebsiella pneumoniae and Streptococcus pneumoniae were $29.1 \%$ and $26.7 \%$, respectively. Next, Pseudomonas aeruginosa accounted for $14 \%$ of cases. Moreover, $K$. pneumoniae, $S$. pneumoniae and $P$. aeruginosa were highly susceptible to $\mathrm{CPZ}$, and susceptibility rates accounted for $88 \%, 82.6 \%$, and $83.3 \%$, respectively.

\section{Therapeutic Effectiveness of CPZ for CAP Patients}

CPZ therapy of 210 CAP cases involved monotherapy for 161 cases $(76.6 \%)$ and combination therapy for 49 cases $(23.4 \%)$. Temperature and signs of clinical 
Table 2: Identified Bacterial Pathogens and Antimicrobial Susceptibilities of CPZ

\begin{tabular}{|c|c|c|}
\hline Pathogens & $\mathbf{N}(\%)$ & Susceptibilities of CPZ (\%) \\
\hline Klebsiella pneumoniae & $25(29.1)$ & $22 / 25(88)$ \\
\hline Streptococcus pneumoniae & $23(26.7)$ & $19 / 23(82.6)$ \\
\hline Pseudomonas aeruginosa & $12(14)$ & $10 / 12(83.3)$ \\
\hline Staphylococcus spp & $11(12.8)$ & $6 / 11(54.5)$ \\
\hline Escherichia coli & $5(5.8)$ & $4 / 5(80)$ \\
\hline Enterobacter aerogenes & $5(5.8)$ & $4 / 5(80)$ \\
\hline Acinetobacter baumannii & $3(3.5)$ & $2 / 3(66.7)$ \\
\hline Citrobacter freundii & $2(2.3)$ & $1 / 2(50)$ \\
\hline Total positive-cultured samples & 86 & \\
\hline
\end{tabular}

instability were recorded over the days of treatment and are shown in Table 3.

The proportions of cases that showed clinical stability by CPZ monotherapy on the third, fifth and seventh day of treatment were $78.9 \%, 87.6 \%$, and $100 \%$, respectively. The mean duration of clinical stability was 3.01 days.

The CPZ therapy achieved a high success rate (72.1\%). Compared with total CPZ susceptibility cases to CAP- causative bacteria, the success rate was higher with 56/68 $=82.3 \%$ (Table 4).

\section{Factors Affecting the Therapeutic Effectiveness}

Table $\mathbf{5}$ shows that age, respiratory rate, and severity category of CAP are significantly associated with the therapeutic effectiveness $(p<0.05)$.
In terms of age, patients under 65 were 4.4 times more likely to achieve treatment effectiveness than patients $\geq$ 65 years old $(p=0.034)$. With respect to respiratory rate, patients with a normal rate were 91 times more likely to achieve therapeutic effectiveness than patients with an abnormal rate $(p=0.0001)$. For patients with varying levels of CAP severity, the odds of achieving therapeutic effectiveness between mild, moderate, and severe categories were statistically significantly different $(p=0.001)$.

\section{DISCUSSION}

Among 142 cultured - CAP samples, 86 samples were culture-positive. The prevalence of CAP due to gramnegative bacteria accounted for $60.5 \%$, higher than the rate of CAP due to gram-positive bacteria with $39.5 \%$. In our study, the elderly $\geq 65$ years old accounted for

Table 3: Proportion of the Patient's Clinical Stability by CPZ Monotherapy

\begin{tabular}{|c|c|c|c|c|}
\hline Signs & $\begin{array}{c}\text { Day } 2 \\
n(\%)\end{array}$ & $\begin{array}{c}\text { Day } 3 \\
n(\%)\end{array}$ & $\begin{array}{c}\text { Day } 5 \\
n(\%)\end{array}$ & $\begin{array}{c}\text { Day } 7 \\
\mathrm{n}(\%)\end{array}$ \\
\hline Body temperature $\leq 37.8^{0} \mathrm{C}$ during 48 hours & $\begin{array}{c}120 \\
(74,5)\end{array}$ & $\begin{array}{c}155 \\
(96,2)\end{array}$ & $\begin{array}{c}161 \\
(100)\end{array}$ & $\begin{array}{c}161 \\
(100)\end{array}$ \\
\hline Only one sign of clinical instability related to CAP & $\begin{array}{c}106 \\
(65,8)\end{array}$ & $\begin{array}{c}127 \\
(78,9)\end{array}$ & $\begin{array}{c}141 \\
(87,6)\end{array}$ & $\begin{array}{c}161 \\
(100)\end{array}$ \\
\hline Clinical stability & $\begin{array}{c}106 \\
(65,8)\end{array}$ & $\begin{array}{c}127 \\
(78,9)\end{array}$ & $\begin{array}{c}141 \\
(87,6)\end{array}$ & $\begin{array}{c}161 \\
(100)\end{array}$ \\
\hline
\end{tabular}

Mean time achieving clinical stability $=3.01$ days.

Table 4: Outcomes of CPZ in CAP Treatment Based on Antibiotic Sensitivity Testing Results

\begin{tabular}{|c|c|c|c|}
\hline \multirow{2}{*}{$\begin{array}{c}\text { CPZ therapy based on } \\
\text { CPZ's susceptibility to } \\
\text { bacteria }\end{array}$} & $\begin{array}{c}|c| \\
\text { Success } \\
\mathbf{n}(\%)\end{array}$ & $\begin{array}{c}\text { Therapeutic results } \\
\mathbf{n}(\%)\end{array}$ & $\begin{array}{c}\text { Total } \\
\mathbf{n}(\%)\end{array}$ \\
\hline \hline Yes & $56(65.12)$ & $12(13.95)$ & $68(79.07)$ \\
\hline No & $6(6.98)$ & $12(13.95)$ & $18(20.93)$ \\
\hline Total & $62(72.10)$ & $24(27.90)$ & $86(100)$ \\
\hline
\end{tabular}


Table 5: Factors Associated with Therapeutic Effects on the $5^{\text {th }}$ Day

\begin{tabular}{|c|c|c|c|c|c|}
\hline \multirow{2}{*}{ Factors } & \multicolumn{2}{|c|}{ Therapeutic effectiveness } & & \multirow{2}{*}{ OR } & \multirow{2}{*}{$p$} \\
\hline & Yes & No & & & \\
\hline Age & $\mathrm{N}(\%)$ & $\mathrm{N}(\%)$ & $\begin{array}{l}\text { Total } \\
\mathrm{n}(\%)\end{array}$ & \multirow[t]{3}{*}{$\begin{array}{c}4.4 \\
(1.0-20.0)\end{array}$} & \multirow[t]{3}{*}{0.034} \\
\hline$<65$ years & $43(95.6)$ & $2(4.4)$ & $45(100)$ & & \\
\hline$\geq 65$ years & $96(82.8)$ & $20(17.2)$ & $116(100)$ & & \\
\hline \multicolumn{4}{|l|}{ Gender } & \multirow{3}{*}{$\begin{array}{c}1.82 \\
(0.70-4.76)\end{array}$} & \multirow[t]{3}{*}{0.212} \\
\hline Male & $64(90.1)$ & $7(9.9)$ & $71(100)$ & & \\
\hline Female & $75(83.3)$ & $15(16.70$ & $90(100)$ & & \\
\hline \multicolumn{4}{|l|}{ Myocardial ischemia } & \multirow{3}{*}{$\begin{array}{c}9 \\
(0.69-116.2)\end{array}$} & \multirow[t]{3}{*}{0.053} \\
\hline Yes & 27 (81.8) & $6(18.2)$ & $36(100)$ & & \\
\hline No & 1(33.3) & $2(66.7)$ & $3(100)$ & & \\
\hline \multicolumn{4}{|l|}{ Hypertension } & \multirow{3}{*}{$\begin{array}{c}9.18 \\
(1.17-71.7)\end{array}$} & \multirow[t]{3}{*}{0.061} \\
\hline Yes & $101(88.8)$ & $11(11.2)$ & $112(100)$ & & \\
\hline No & $2(50)$ & $2(50)$ & $4(100)$ & & \\
\hline \multicolumn{4}{|l|}{ Albumin $(g / L)$} & \multirow{3}{*}{$\begin{array}{c}1.12 \\
(0.237-5.303)\end{array}$} & \multirow[t]{3}{*}{0.622} \\
\hline Normal (35-50) & $14(87.5)$ & $2(12.5)$ & $16(100)$ & & \\
\hline Abnormal & $125(86.2)$ & $20(13.8)$ & $145(100)$ & & \\
\hline \multicolumn{4}{|l|}{ BUN (mmol/L) } & \multirow{3}{*}{$\begin{array}{c}1.065 \\
(0.427-2.657)\end{array}$} & \multirow[t]{3}{*}{1} \\
\hline Normal $(2,7-7,5)$ & $59(86.8)$ & $9(13.2)$ & $68(100)$ & & \\
\hline Abnormal & $80(86)$ & $13(14)$ & $93(100)$ & & \\
\hline \multicolumn{4}{|l|}{ Creatinin (mmol/L) } & \multirow{3}{*}{$\begin{array}{c}2.58 \\
(0.63-10.6)\end{array}$} & \multirow[t]{3}{*}{0.173} \\
\hline Normal & $131(87.3)$ & $19(12.7)$ & $150(100)$ & & \\
\hline Abnormal & $8(72.7)$ & $3(27.3)$ & $11(100)$ & & \\
\hline \multicolumn{4}{|l|}{ CRP (mg/L) } & \multirow{3}{*}{$\begin{array}{c}0.21 \\
(0.033-1.33)\end{array}$} & \multirow[t]{3}{*}{0.129} \\
\hline Normal $(<5 m g / L)$ & $3(60)$ & $2(40)$ & $5(100)$ & & \\
\hline Abnormal & $136(87.7)$ & $19(12.3)$ & $155(100)$ & & \\
\hline \multicolumn{4}{|l|}{$\mathrm{PaO}_{2}$} & 2.48 & 0.698 \\
\hline Normal(80-100 mmHg) & $14(93.3)$ & $1(6.7)$ & $15(100)$ & & \\
\hline Abnormal & $124(84.9)$ & $22(15.1)$ & $146(100)$ & & \\
\hline $\begin{array}{c}\text { Respiratory } \\
\text { rate(breaths/minute) }\end{array}$ & & & & $\begin{array}{c}91.12 \\
(23.89-347.4)\end{array}$ & 0.0001 \\
\hline Normal (18-20) & $134(96.4)$ & $5(3.6)$ & $139(100)$ & & \\
\hline Abnormal & $5(22.7)$ & $17(77.3)$ & $22(100)$ & & \\
\hline Severity categories of CAP & & & & & 0.001 \\
\hline Mild & $36(94.7)$ & $2(5.3)$ & $38(100)$ & & \\
\hline Moderate & $96(87.3)$ & $14(12.7)$ & $110(100)$ & & \\
\hline Severe & $7(53.8)$ & $6(46.2)$ & $13(100)$ & & \\
\hline
\end{tabular}

Note: BUN (blood urea nitrogen); CRP (C-reactive protein).

$72 \%$. Therefore, the study on the elderly in Beijing, China, conducted by Ying Luan et al. and our study has similar results that Gram-negative bacteria are the main pathogenic bacteria in older patients acquiring
CAP [13]. In terms of etiology, $K$. pneumoniae CAP in this study accounted for the highest prevalence rate of $29.1 \%$, higher than the rate of $23 \%$ in Malaysia / Singapore, and the rate of $13 \%-18 \%$ in Thailand [13]. 
Over the past two decades, K. pneumoniae has become one rare cause of CAP in North America, Europe, and Australia. However, it remains an important cause of CAP in Asia [14]. An increase in the incidence of $K$. pneumoniae CAP in Asia could reflect the effect of different environmental conditions on transmission, or it could be an increase in the frequency of host factors such as abnormal nutritional status, comorbidities, or genetic background that can facilitate $K$. pneumoniae infection. In these regions, patients also have a classic risk factor of alcoholism because $K$. pneumoniae is traditionally associated with alcoholism [15]. After K.pneumoniae- CAP, the secondranked prevalence rate was S.pneumoniae - CAP, accounting for $26.7 \%$. This rate is consistent with prevalence rates in the United States, Hong Kong, and Thailand, with rates ranging from $26 \%-41 \%, 22 \%$ $30 \%$, and $20 \%-31 \%$, respectively [14]. This study showed that the etiology of CAP has been changing. $S$. pneumoniae is not still the most frequently identified pathogenic bacteria in adults, similar to Malaysia / Singapore and Thailand [14]. Next, the third-ranked prevalence of $P$.aeruginosa-CAP accounted for $14 \%$ of culture-positive CAP. This rate is lower than a $19 \%$ prevalence of $P$.aeruginosa in hospitalized patients with CAP in the United States [16]. However, it is higher than a $2.2 \%$ prevalence among patients with positive cultures in Europe [17] and a 0.4\% prevalence of adult patients with CAP in the United States [18]. Variations in the prevalence rates reported by different studies may be explained by differences in study design and different environments (i.e., single hospital, region, country, or continent) with specific differences in healthcare delivery, including antibiotic availability and policies for antimicrobial use [19].

In terms of antimicrobial properties, CPZ has a broad spectrum of activity against gram-negative bacteria and gram-positive cocci. Our results showed that CPZ alone showed good activity against most species of K.pneumoniae, E.coli, and P.aeruginosa with antimicrobial susceptibility rates of $88 \%, 80 \%$, and 83.3, respectively. In our study, the antimicrobial susceptibility rate of $\mathrm{CPZ}$ is higher than the rates of CPZ against K.pneumoniae (64.9\%) and P.aeruginosa (75.8\%) in Taiwan [20]. In China, drug susceptibilities of major gram-negative bacteria to $\mathrm{CPZ}$ were also lower such as K.pneumoniae with $56.3 \%$, E.coli (42.9\%), and P.aeruginosa (71.4\%) [13]. This means that CPZ is highly susceptible to the main pathogenic bacteria (Gram-negative bacteria) among older CAP cases in Vietnam. This can be explained by not abusing $\mathrm{CPZ}$ in the treatment of $\mathrm{CAP}$.
Regarding the therapeutic effectiveness of CPZ monotherapy, the success rate of treatment based on the antibiotic sensitivity testing results accounts for $65.12 \%(56 / 86$ cases $)$, higher than the rates of $50 \%$ and $35.5 \%$ of 2 studies conducted in Vietnam [21, 22]. The reason can be explained that the isolates are still very sensitive to $C P Z$ due to the less common use in primary care settings and the high prevalence of CPZsensitive Gram-negative bacteria in the study samples. The mean time to achieve clinical stability is 3.01 days. Compared with a study on nursing home-acquired pneumonia in the USA, the mean time of therapy effectiveness is 10.75 days [23]. The difference in the mean time of effective treatment may originate from the different proportions of older adults over 65 years of age, common isolates from samples, and rates of comorbidities. The proportion of patients achieving clinical stability on day 3 of treatment was $78.9 \%$, on day 5: $87.6 \%$, and on day $7: 100 \%$ of total cases were treated with the CPZ monotherapy. Our result is slightly higher than the results of the study conducted by Halm et al. (3rd day: $77 \%$, 4th day: 86\%) [24], clearly higher than the study by Rosario et al. (58.2\% on day 4 ) [25].The significant difference could be explained due to reasons: (1) Rosario chose $\leq 37.2 \mathrm{C}$ instead of $\leq$ $37.8 \mathrm{C}$ as a determining factor of clinical stability, (2) their patients were older and more severely ill than our patients. This indicates that the patient responded well to the CPZ monotherapy in our study. Regarding factors affecting the therapeutic effectiveness, the Chisquare test showed that three factors associated with the effectiveness of $\mathrm{CPZ}$ monotherapy, including the age of patients, respiratory rate, and severity categories of CAP classified by the British Thoracic Society's CURB-65 score. Increasing age is a predictor of a poor prognosis in CAP patients as well as influences the treatment [26]. Age is included as a prognostic factor in the PSI [27], CURB-65 [28], and ADROP scoring system [29]. Therefore, increasing age is also a poor prognostic factor for CAP. Next, respiratory status is considered a poor prognostic factor of CAP and affects therapeutic effectiveness [26]. It is included in all pneumonia severity scores, and respiratory rate is adopted in CURB-65 [28]. Finally, the CAP severity based on CURB-65 scores not only affects the therapeutic effectiveness but is also considered a predictor of mortality [30]. The finding of our study highlights the most attention on the severe category of pneumonia due to the lowest rates of treatment success.

This study has some limitations. Firstly, it was a retrospective study, so the outcome depends on the 
availability of secondary data in medical records. For instance, data related to the identification of pathogens and their susceptibility to CPZ were available in 86 medical records, accounting for $41 \%$ of total cases. Therefore, we were not able to evaluate the effect of causative pathogens and their resistance to CPZ on the treatment outcomes in the full study population. Next, we only mentioned bacterial pathogens, not including pneumonia-causing viruses, since serological tests were not routinely performed in hospitals.

\section{CONCLUSION}

The prevalence of pneumonia caused by $K$. pneumoniae in the community is the highest among the elderly hospitalized at tertiary care hospitals in Vietnam. Research on the virulence of $K$. pneumoniae to produce vaccines for the elderly in the coming time is necessary. CPZ is still sensitive to Gram-negative bacteria and Gram-positive cocci as there is proven effectiveness of CPZ monotherapy on day 3, with nearly $80 \%$ of patients achieving clinical stability. Although CPZ seemed to be a good choice of therapy, it is important to minimize CPZ resistance and CPZ overuse leading to the influence on the therapeutic effectiveness in the future. During hospitalization, the factors associated with the success of achieving clinical stability are age below 65 years old, normal respiratory rate (18-20 breaths/min), and mild or moderate categories of CAP severity based on CURB-65 scores. These identified factors are useful for clinicians in predicting the prognosis of CAP patients, planning the sequential therapy, and determining hospital discharge.

\section{ACKNOWLEDGEMENTS}

The authors would like to express their sincere thanks to the Kien Giang Hospital Management Board and all colleagues for their help and permission on access to medical records in this study.

\section{FUNDING}

No financial support has been received for this study.

\section{DISCLOSURE}

The author reports no conflicts of interest in this work.

\section{REFERENCES}

[1] Canan G, Mehmet ST, Abdullah S, Aykut Ç, Oğuz K, Ayşın ŞC. Factors affecting treatment success in communityacquired pneumonia. Turk J Med Sci 2016; 46(5): 14691474.

https://doi.org/10.3906/sag-1502-87
[2] Navdeep KB, Michael SN. Management of communityacquired pneumonia: a review and update. Ther Adv Respir Dis $2010 ; 5(1)$ : 61-78. https://doi.org/10.1177/1753465810381518

[3] Peto L, Nadjm B, Horby P.The bacterial etiology of adult community acquired pneumonia in Asia: a systematic review. Trans R Soc Trop Med Hyg 2014; 108: 326-337. https://doi.org/10.1093/trstmh/tru058

[4] Antonella FS, Diego V, Carolina GV, Jordi C. Management of community-acquired pneumonia in older adults. Therapeutic Advances in Infectious Disease 2014; 2(1): 3-16. https://doi.org/10.1177/2049936113518041

[5] Ying L, Yuling S, Shuhong D, Ping Z, Zhongying B. Pathogenic bacterial profile and drug resistance analysis of community-acquired pneumonia in older outpatients with fever. J Int Med Res 2018; 46(11): 4596-4604. https://doi.org/10.1177/0300060518786915

[6] Rxlist. Drug Description.Cefobid.Available from: https://www.rxlist.com/cefobid-drug.htm

[7] Vietnamese Ministry of Health.Vietnam National Pharmacopoeia. $5^{\text {th }}$ ed. Hanoi 2018.

[8] Jien WL, Yen HC, Wen SL, Jung CL, Ching TH, His HL, et al. Randomized Noninferiority Trial of Cefoperazone-Sulbactam versus Cefepime in the Treatment of Hospital-Acquired and Healthcare-Associated Pneumonia. Antimicrob Agents Chemother 2019; 63(8): 19-23. https://doi.org/10.1128/AAC.00023-19

[9] Vietnamese Ministry of Health. Guidelines for Antibiotic Uses 2015; 93-98

[10] Ethan AH, Michael JF, Thomas JM, Christopher MC, Wishwa NK, D Scott O, et al. Time to Clinical Stability in Patients Hospitalized With Community-Acquired Pneumonia Implications for Practice Guidelines. JAMA 1998; 279(18): 1452-1457.

https://doi.org/10.1001/jama.279.18.1452

[11] Lionel AM, Richard GW, Antonio A, John GB, Douglas C, Nathan CD, et al. Infectious Diseases Society of America/American Thoracic Society Consensus Guidelines on the Management of Community-Acquired Pneumonia in Adults. Arch.Clin.Infect. Dis. 2007; 44 (Supplement_2): S27S72.

[12] MDCALC. CURB-65 Scores for pneumonia severity. Available from: https://www.mdcalc.com/curb-65-scorepneumonia severity\#: $:$ text=The $\% 20$ CURB \%2D65\%20calculator\%20can,to\%20a\%20variety\%20of\%20f actos

[13] Ying L, Yuling S, Shuhong D. Pathogenic bacterial profile and drug resistance analysis of community-acquired pneumonia in older outpatients with fever. Int $\mathrm{J}$ Med Res 2018; 46(11): 4596-4604.

https://doi.org/10.1177/0300060518786915

[14] Brown JS. Geography and the aetiology of community acquired pneumonia. Respirology 2009; 14 (8): 1068-1071. https://doi.org/10.1111/j.1440-1843.2009.01641.x

[15] Ko WC, Paterson DL, Sagnimeni AJ.Community-acquired Klebsiella pneumoniae bacteremia: global differences in clinical patterns. Emerg Infect Dis 2002; 8: 160-166. https://doi.org/10.3201/eid0802.010025

[16] Kollef MH, Shorr A, Tabak YP. Epidemiology and outcomes of health-care-associated pneumonia: results from a large US database of culture-positive pneumonia. Chest 2005; 128: 3854-3862. https://doi.org/10.1378/chest.128.6.3854

[17] Chalmers JD, Taylor JK, Singanayagam A. Epidemiology, antibiotic therapy, and clinical outcomes in health careassociated pneumonia: a UK cohort study. Clin Infect Dis 2011; 53: 107-113.

https://doi.org/10.1093/cid/cir274 
[18] Jain S, Self WH, Wunderink RG. Community-acquired pneumonia requiring hospitalization among $\mathrm{U}$. S. adults. $\mathrm{N}$ Engl J Med 2015; 373: 415-427. https://doi.org/10.1056/NEJMoa1500245

[19] Aliberti S, Reyes LF, Faverio P. Global initiative for meticillinresistant Staphylococcus aureus pneumonia (GLIMP): an international, observational cohort study. Lancet Infect Dis 2016; 16: 1364-1376. https://doi.org/10.1016/S1473-3099(16)30267-5

[20] Tsung TC, Hung JT, Cheng HC, Te LC, Mao WH, Chen HL, et al. Antimicrobial Activities of Cefoperazone-sulbactam in Comparison to Cefoperazone against Clinical Organisms from Medical Centers in Taiwan. J Med Sci 2016; 36(6): 229233. https://doi.org/10.4103/1011-4564.196365

[21] Duong L H, Pham P L. Current situation of antibiotic use in treating adult pneumonia at I Agricultural Hospital. Viet J Public Health.2013; 31-39.

[22] Cao X T. Evaluation of appropriate antibiotic treatment efficacy in severe pneumonia in the respiratory department of Cho Ray hospital. J Med of HCM city.2009; 14: 142-147.

[23] Syed IA, Nadia H, Claire P, Patrick M, Duane R, Robert W. et al. Nursing home-acquired pneumonia: course and management in the emergency department. Int J Emerg Med 2014; $7: 19$ https://doi.org/10.1186/1865-1380-7-19

[24] Halm EA, Fine MJ, Marrie TJ. Time to clinical stability in patients hospitalized with community-acquired pneumonia: implications for practice guidelines. JAMA 1998; 279(18): 1452-1457.

https://doi.org/10.1001/jama.279.18.1452
[25] Rosario M, Antoni T, Felipe RC, Rafael Z, Javier A, Juan JV et al. Reaching Stability in Community-Acquired Pneumonia: The Effects of the Severity of Disease, Treatment, and the Characteristics of Patients. Clin.Infect. Dis 2004; 39 (12): 1783-1790. https://doi.org/10.1086/426028

[26] Akihiro I, Tadashi I, Hironobu T, Yasuyoshi W, Akio Y, Yuhei $\mathrm{I}$, et al. Prognostic factors in hospitalized community-acquired pneumonia: a retrospective study of a prospective observational cohort. BMC Pulm 2017; 17(1): 78-79. https://doi.org/10.1186/s12890-017-0424-4

[27] Majhi A, Kundu K, Adhikary R. Combination therapy with ampicillin and azithromycin in an experimental pneumococcal pneumonia is bactericidal and effective in down regulating inflammation in mice. J Inflamm 2014; 11(1): 5 . https://doi.org/10.1186/1476-9255-11-5

[28] Lim WS, Eerden van der MM, Laing R. Defining community acquired pneumonia severity on presentation to hospital: an international derivation and validation study. Thorax 2003; 58(5): 377-382.

https://doi.org/10.1136/thorax.58.5.377

[29] Miyashita N, Matsushima T, Oka M. Japanese Respiratory Society. The JRS guidelines for the management of community-acquired pneumonia in adults: an update and new recommendations. Intern Med 2006; 45(7): 419-428. https://doi.org/10.2169/internalmedicine.45.1691

[30] Sirvent JM, Carmen TM, Lorencio C. Predictive factors of mortality in severe community-acquired pneumonia: a model with data on the first $24 \mathrm{~h}$ of ICU admission. Med Intensiva 2013; 37: 308-315.

https://doi.org/10.1016/j.medin.2013.03.003 